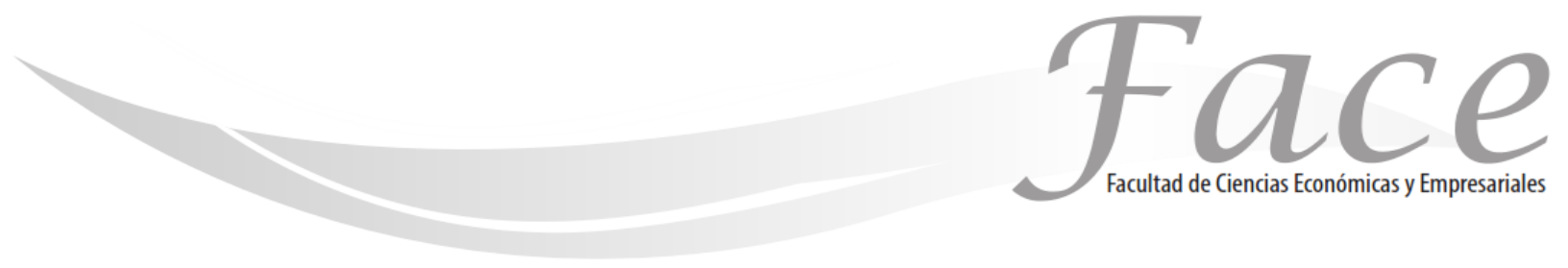

ISSN Impreso: 1794-9920

ISSN Electrónico: 2500-9338

Volumen 19-N¹

Año 2019

Págs. 7 - 15

\title{
LA MERCADOTECNIA EN LAS FESTIVIDADES RELIGIOSAS CASO: NIÑOPA, XOCHIMILCO, MÉXICO
}

\author{
Dra. Laura Estela Fischer de la Vega * \\ ORCID: http://orcid.org/0000-0002-5791-6058
}

Fecha de Recepción: Enero 27 de 2019

Fecha de Aprobación: Mayo 17 de 2019

\section{Resumen:}

Con el objetivo de conocer la importancia mercadológica que tienen las festividades religiosas en la derrama económica de los habitantes de una localidad, así como el impacto social y cultural de las mismas se realizó un estudio cualitativo, etnográfico y descriptivo de la celebración de la festividad del Niñopa que se realiza en Xochimilco, municipio de la Ciudad de México, México; esta celebración es la más importante de la localidad y parte importante de la cultura y tradición mexicana; Como resultado se encontró que la mercadotecnia está presente de manera empírica en cada una de las acciones que se realizan en esta importante festividad religiosa, resultando un atractivo turístico que genera una fuente significativa de recursos económicos para el lugar.

Palabras clave: mercadotecnia religiosa, festividades religiosas.

\footnotetext{
* Doctora en Ciencias Sociales y Administrativas, Universidad Chapultepec: Mexico, Distrito Federal, Maestría en Ciencias de la Comunicación, Universidad Nacional Autónoma de México; Universidad Nacional Autónoma de México; Licenciada en Administración de Empresas. Profesora adscrita a la Facultad de Contaduría y Administración de la UNAM - México. Contacto: Ifischer@fca.unam.mx
} 


\title{
MARKETING ON RELIGIOUS FESTIVITIES, CASE: NIÑOPA, XOCHIMILCO, MÉXICO
}

\begin{abstract}
:
A qualitative, ethnographic and descriptive study of the celebration of the Niñopa festival was carried out with the purpose of knowing the market importance of the religious festivals in the economic flow of the inhabitants of a locality, as well as the social and cultural impact of them. made in Xochimilco, Mexico City, Mexico; This celebration is the most important of the locality and an important part of the Mexican culture and tradition; As a result, it has been found that marketing is empirically present in each of the actions carried out in this important religious festival, resulting in a tourist attraction that generates a significant source of economic resources for the place.
\end{abstract}

Keywords: Religious Marketing, Religious Festivities.

\section{MARKETING SOBRE FESTIVIDADES RELIGIOSAS, CASO: NIÑOPA, XOCHIMILCO, MÉXICO}

\section{Resumo:}

Um estudo qualitativo, etnográfico e descritivo da celebração do festival Niñopa foi realizado com o objetivo de conhecer a importância do mercado das festas religiosas no fluxo econômico dos habitantes de uma localidade, bem como o impacto social e cultural das mesmas. . feito em Xochimilco, Cidade do México, México; Esta celebração é a mais importante da localidade e uma parte importante da cultura e tradição mexicana; Como resultado, foi encontrado empiricamente presente em cada uma das ações realizadas neste importante festival religioso, resultando em uma atração turística que gera uma fonte significativa de recursos econômicos para o local.

Palavras-chave: marketing religioso, festividades religiosas. 


\section{INTRODUCCIÓN:}

La religión es una parte importante del quehacer humano; los orígenes de los pueblos en la antigüedad se desarrollaron en función de la religión que se profesaba; el comercio, albergues, lugares de comidas iniciaron con las peregrinaciones que hacían los fieles hacía los lugares donde había aparecido alguna virgen, se tenía alguna reliquia de un santo o había sucedido algún "milagro"; por lo tanto, la religión está íntimamente vinculada desde su origen con la historia de los pueblos que la profesan. La historia es el reflejo de la vida cotidiana de las personas a través del tiempo; la religión es parte importante de la cultura, dirá lo que es debido, lo indebido, lo autorizado y lo prohibido; además, determinará pautas de conducta que serán seguidos por todas las personas que profesan esa religión y, ello, permeará en toda la sociedad.

Cuando se trata de una misma fe, las actividades de pertenencia a una misma religión se practican a partir de un hábito religioso común, íntimo y espontáneo, sin barreras idiomáticas; por ejemplo: asistir a misa, rezar en una iglesia, participar de una peregrinación, festividad o de un vía crucis; esto constituye la oferta básica de actividades religiosas con lenguaje o código universal con prácticas parecidas de fácil interpretación, sin barrera de nacionalidad. Aun en el caso de las religiones orientales, de características más estrictas y tradicionales, a consecuencia de las migraciones hacia occidente en búsqueda de mejores condiciones de vida podemos encontrar actualmente practicantes diseminados por el mundo.

Desde tiempos inmemoriales, los desplazamientos de grandes grupos de personas por motivos de fervor y devoción religiosa han estado presentes en la humanidad sin importar sexo, credo o estrato social. En la actualidad, millones de peregrinos anualmente realizan este tipo de viajes a diversos y muy variados santuarios, los motivos que encierran son distintos, como pueden ser para ofrendar algo, pedir un favor o por cumplir una promesa, o simplemente por tradición familiar o como parte de su grupo cultural.

Las festividades religiosas se han colocado como una actividad que cada ciudad, pueblo o país - sin importar la religión que profese-ha utilizado para crear identidad entre la comunidad, lo que viene a representar la cultura de cada nación.
Este trabajo tiene como objetivo conocer, a través de un caso, como las festividades religiosas y la mercadotecnia que se realiza en ellas llega a ser una derrama económica para muchas localidades, que ven en estos festejos una forma de atraer un tipo de turismo y de beneficiarse económicamente

La investigación consta de cuatro partes, en la primera se encuentra el marco teórico, que sustenta a la mercadotecnia religiosa y la importancia de las festividades religiosas; la segunda presenta el caso del Niñopa, una festividad religiosa que se lleva a cabo en Xochimilco, municipio de la Ciudad de México, México; la tercera muestra, a través del estudio etnográfico y entrevistas a las personas que llevan a cabo esta celebración, la importancia en el desarrollo económico y social de la localidad, así como los aspectos mercadológicos que involucra esta festividad; por último, se presentan las conclusiones

\section{MARCO TEÓRICO:}

El marketing religioso se concentra en la adquisición y retención de fieles. Hamberg y Pettersson (2001) señalan que la tendencia que mantiene el mercado religioso es semejante a la que se da en mercados de bienes y servicios, considerando la producción religiosa como un bien u otro tipo de servicio que el consumidor demanda.

Para Sanjay y Gurinderjit (1995) los conceptos y principios de la mercadotecnia pueden ser aplicados a organizaciones religiosas como la Iglesia; estos principios son mencionados por Hansen, Ross, (2002), quienes resaltan el hecho de que existen pocas investigaciones sobre este tema; afirman que las iglesias no han sentido la necesidad de comercializar su producto. Sanjay et al. (1995) confirman lo mencionado por Kotler y Amstrong (2012) acerca de que en la mercadotecnia el objetivo principal es la satisfacción de los clientes; además de que es un factor determinante en las compras repetitivas; sobre ello, el mismo clero está empezando a entender la importancia de la mercadotecnia y en ocasiones la relaciona con las ventas (Aguilar 2008).

El marketing religioso se utiliza para la divulgación de un producto en particular y la conversión de los miembros. Así, los representantes de estas congregaciones tienen un instrumento eficaz en el competitivo mercado religioso; por lo tanto, la mercadotecnia religiosa, dentro de la mezcla de mercadotecnia, puede considerarse un proceso que se materializa en el análisis de mercados, su desarrollo y en la 
producción de productos o servicios religiosos adecuados, que - por supuesto- deben ir acompañados de una comunicación efectiva para satisfacer las necesidades espirituales sin dejar de lado las metas particulares de la organización (Abreu, 2006).

El marketing se define como la actividad que busca satisfacer necesidades - no crearlas - y la necesidad de creer en algo, de espiritualidad, de tener una guía, es de las más grandes y antiguas de la humanidad.

En el mundo existen un gran número de religiones con billones de fieles, que pueden ser creyentes activos (que siguen todas las normas religiosas) 0 creyentes pasivos (que siguen algunas o ninguna norma religiosa, pero que se consideran que profesan alguna religión), La religión católica romana es practicada por 1.05 billones (Marketing religioso, 2018)

México es un país católico religión que es profesada por 92 millones 924 mil 489 personas, existiendo 3,223 asociaciones religiosas católicas y 68,041 ministros de culto (INEGI, 2010) la Iglesia católica tiene más de 365 santos que se veneran; ejemplo de ello es la existencia de más de cien pueblos llamados San Juan, San José o Santa María, por lo que seguramente habrá alguna gran celebración en cada uno de esos sitios en el día del santo patrón. Así, pues, es prácticamente imposible enlistar cada una de las celebraciones de los pueblos de México, pero sí es posible asegurar que se encontrará una celebración o festividad religiosa a la cual asistir en cualquier día del año (pueblosméxico 2018).

Las festividades religiosas son manifestaciones culturales que transforman la decoración de los espacios públicos. Plazas y calles se llenan de colorido con puestos de comida, feria con juegos mecánicos, puestos con venta de artesanías y productos de la localidad, conciertos, bailes y desfiles, tanto religiosos como civiles que desaparecerán con el final de la fiesta. En todas estas celebraciones se encuentra inmersa la mercadotecnia, aunque no sea llamada de esta forma; por ejemplo, en los rituales que maneja, en la planeación y la organización para que la fiesta se realice, en la comercialización de un gran número de productos que son necesarios para llevar a cabo los festejos, en el número de atracciones secundarias que derivan de estas celebraciones, como son la puesta de ferias, juegos mecánicos, mayor consumo de alimentos, de ropa, de alojamiento, entre muchos otros productos que son derivados de estas celebraciones religiosas.
Para conocer la importancia mercadológica que tienen las festividades religiosas en la derrama económica de los habitantes de la localidad, así como el impacto social y cultural de las mismas, se realizó un estudio cualitativo etnográfico, descriptivo de la celebración de la festividad del Niñopa que se lleva a cabo en Xochimilco, municipio de la Ciudad de México, México; así mismo, se efectuaron entrevistas a los principales participantes en dicha celebración (mayordomo, chinela y encargado del festejo por parte de la alcaldía de Xochimilco).

\subsection{Xochimilco}

\subsubsection{Aspectos generales}

Es una de las 16 alcaldías de la Ciudad de México. Se localiza en el sureste de la capital mexicana y posee una superficie de $122 \mathrm{~km}^{2}$, lo que representa el $7.9 \%$ de la superficie total de la Ciudad de México. La delegación limita al norte con los territorios de Coyoacán e Iztapalapa; al oriente, con Tláhuac; al sur, con Milpa Alta; y al poniente, con Tlalpan; Xochimilco es una de las alcaldías más marginadas, aunque no en todo su territorio. En el noroeste, en el límite con Tlalpan y Coyoacán, se localizan fraccionamientos de reciente creación que poseen todos los servicios urbanos. Su población es predominantemente de clase media, tanto por los niveles de escolaridad como por el ingreso. Pero en los pueblos chinamperos, y especialmente en las colonias populares de la sierra, existen amplias zonas donde escasea el agua potable, no hay pavimentación y los servicios sociales son insuficientes. Esta situación se ve agudizada por la distancia con respecto al núcleo de la Ciudad de México.

Su población es de 415007 (INEGI, 2010), 49\% de hombres y $51 \%$ de mujeres; su porcentaje de alfabetismo es cercano al promedio capitalino, que en el mismo censo fue de $97 \%$. De la población alfabetizada, el $68 \%$ tenía algún tipo de instrucción posterior al nivel primario.

En relación con las festividades religiosas, destaca en la cultura popular xochimilca el hecho de ser un lugar de fiesta continua. Siempre hay algo que conmemorar 0 alguna imagen que venerar. Se dice que hay 365 fiestas al año, todos los pueblos y barrios de la región tiene su celebración al Santo Patrono; ejemplo de ello son: San Gregorio Magno, el Santísimo, la Candelaria, la Virgen del Carmen, la Purísima, el Niño Dios del Pueblo, la Virgen de la Concepción, el Sagrado Corazón y la Virgen de Guadalupe y los Santos de cada barrio - hay alrededor de 30 barrios-, así como otros festejos al Santuario del Señor de Chalma, al Niño Dios del Pueblo y otros niños locales (barriales e invitados) de Belén, de las Azucenas, entre muchos otros. (Landázuri, 2014). De los santos venerados en los barrios de Xochimilco que tienen su propia celebración, destaca una festividad que es realizada por la 
Dra. Laura Estela Fischer de la Vega

mayoría de los habitantes de Xochimilco y que no sólo los involucra, sino a las autoridades municipales, eclesiásticas y culturales; es una festividad que dura 365 días y que involucra aspectos económicos, mercadológicos, culturales y religiosos que han permanecido en el tiempo y se siguen de generación en generación, esta festividad es la del Niñopa (Mexicodesconocido 2018).

\subsection{Festividad religiosa Niñopa}

El nombre de la imagen es Niñopa, que es un vocablo híbrido hispano-náhuatl que se traduce como Niño del Pueblo (del español niño y el náhuatl pan, lugar). Por otra parte, el nombre de Niñopa significa en la etimología popular como niño padre, donde -pa es apócope de padre, es una imagen que pertenece a los xochimilcas y no a la Iglesia Católica, como muchas otras imágenes de santos

La escultura del Niñopa representa a un niño Dios desnudo con un cendal azul cerúleo alrededor de la cadera, mide 51 centímetros de largo y pesa 598 gramos. Se sabe que el Niñopa fue esculpido en palo de colorín por un artesano indígena en el siglo XVI. Sus ojos dan sensación de tristeza, pues se encuentran rasgados y ligeramente extendidos hacia abajo; pero la boca es excepcional: pequeña y entreabierta como si emitiera un ligero sonido; el labio superior es de color rojo, más intenso que el inferior.

Dentro de las características que distinguen al Niñopa se puede apreciar que tiene cabello pintado de color castaño, con dos entradas pronunciadas y un copete en medio de ellas. En la parte superior de la cabeza tiene tres agujeros, dos de ellos arriba de cada oreja y uno en medio donde se colocan las potencias de metal que se desprenden y simbolizan la santísima trinidad (Figura 1).
La imagen es considerada milagrosa y se le rinde culto desde hace siglos; sus actividades rituales se llevan a cabo durante todos los días del año; tiene un constante peregrinar por pueblos y barrios de Xochimilco, donde es llevado para realizar visitas a los domicilios de quienes lo hayan solicitado por diversas razones: festejarle alguna de sus actividades ya establecidas en el ciclo ritual, agradecerle por algún favor concedido, resolver algún problema, o por la satisfacción que provoca en sus fieles el hecho de tenerlo en sus casas.

En la celebración del Niñopa participan el mayordomo, los nueve posaderos, la comparsa de chinelos, la estudiantina, los encargados de la adoración y arrullo, las cuidanderas del Niñopa y las autoridades gubernamentales y eclesiásticas.

Los mayordomos son los responsables de custodiar y cuidar al Niñopa durante el año que dura su mayordomía; es una labor que realizan voluntariamente y que ejecutan con base en tres lineamientos. El primero de estos lineamientos es creado por la Comisión Coordinadora del Niñopa (CCN) y refiere a las obligaciones que un mayordomo tiene tanto con la imagen, como con el culto y los devotos; el segundo, emana de la Iglesia Católica que junto la Comisión Coordinadora elaboran el documento conocido como Decálogo del Mayordomo; el tercero, emana del Instituto Nacional de Antropología e Historia, una institución del Gobierno que busca normar el manejo de la imagen por ser considerada parte del patrimonio nacional.

Para ser mayordomo hay que esperar alrededor de 40 años, por lo que algunos registran a sus hijos o nietos para que sean ellos en caso de su fallecimiento, los responsables de recibir al Niñopa.

Figura 1: NiñoPa de Xochimilco

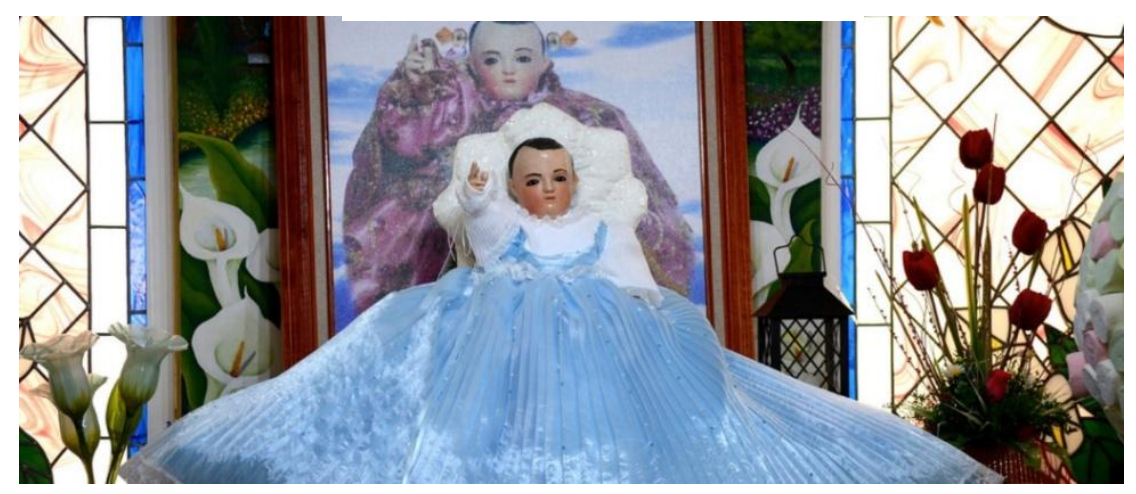

Fuente: Redacción ADN40 Abril 2017 
Para llevar a cabo la mayordomía convocan a la constitución de comisiones de trabajo voluntario para implementar las tareas que se desprenden de su cargo. Estas comisiones están integradas por familiares, amigos y vecinos de los mayordomos, además de varios devotos del Niñopa; por este motivo, años antes de asumir la mayordomía se encargan de seleccionar e invitar a personas de su confianza que cuenten con prestigio al interior de su localidad y con la solvencia económica que les permita pagar la festividad, ya que los mayordomos durante el tiempo que tienen al Niñopa suelen dejar sus trabajos para dedicarse completamente al cuidado de la imagen. Por lo tanto, deben contar con un apoyo económico suficiente que les permita financiar todos los gastos durante este periodo. Precisar el costo total que tiene la mayordomía para un custodio de la imagen resulta casi imposible, pero sí se puede mencionar que es un gasto fuerte superior a $\$ 500,000.00$, ya que implica pagar la mayor parte de las fiestas del Niñopa: dar comida gratuita a todas las personas que asisten, pagar las misas, rentar o comprar equipo de audio, mesas, sillas, altares, portadas, vehículos, implementos de cocina, tarimas, lonas, pagar la pirotecnia y contratar grupos de música, entre muchas otros gastos derivados de los festejos, aunque los gastos principalmente recaen en el mayordomo, la comunidad de familiares, amigos, vecinos y devotos del Niñopa los ayudan donándoles comida, dinero, mano de obra voluntaria, materiales de construcción para adaptar su hogar, artículos rituales, entre otros. La solidaridad y ayuda de la comunidad es fundamental para llevar a cabo esta celebración. Salles y Valenzuela (1997:193), mencionan que: "Esta colaboración, además de tener un sentido social, se asume como una actividad necesaria para satisfacer y honrar a las fuerzas divinas."

Además de los mayordomos, que son los representantes principales de la imagen, existen los posaderos del Niñopa, personas responsables de organizar, sufragar y realizar una de las nueve posadas que se efectúan en honor a la imagen del 16 al 24 de diciembre en el contexto de los festejos navideños. La temporalidad del cargo de posadero dura un periodo e ingresan y salen con los mayordomos de turno.

El posadero asume gran parte del costo total de la posada, lo cual implica costear la comida, la vestimenta de la imagen, la pirotecnia, la infraestructura ritual, la música, la misa, los estandartes, las invitaciones, entre otros gastos. Por tal razón, durante los años previos a la posada, los posaderos se encargan de juntar los recursos económicos y materiales necesarios para poder solventar la celebración. Al igual que los mayordomos, muchos contraen deudas o generan estrategias alternas a sus trabajos habituales que les permitan tener un excedente apropiado.
Otros actores que participan en las celebraciones del Niñopa en el Día de la Candelaria y en las nueve posadas son los danzantes o chinelos, que pueden llegar a ser más de 50 individuos, integrada por hombres y mujeres de cualquier edad. Las personas que participan como chinelos generalmente lo hacen para pagar alguna manda, por tradición familiar o por el gusto de bailar y/o poder compartir con el Niñopa. Como requisito para ser chinelo la mayordomía le exige contar con su propio traje, aprender la danza y comprometerse a dedicar parte de su tiempo a las actividades donde sean requeridos — procesiones y misas. Cabe señalar que cada comparsa de chinelos cuenta con coordinadores, encargados de seleccionar, capacitar y dirigir a los miembros del grupo.

Dentro de las festividades también participa la estudiantina, integrada principalmente por jóvenes y niños que se ofrecen de manera voluntaria para tocar y cantar durante un año en las actividades que la mayordomía realiza en honor al Niñopa como son misas, rosarios y procesiones. Los integrantes de la estudiantina van vestidos con trajes europeos antiguos, similares a los del siglo XVI.

También existe la comisión de seguridad del Niñopa, grupo integrado por parientes de los mayordomos y devotos de la imagen, en su mayoría hombres adultos, que de manera voluntaria apoyan en las tareas de orden y seguridad.

Los hospederos son las personas que reciben por un día la visita del Niñopa en sus hogares. Es una labor que realizan "voluntariamente" tanto hombres como mujeres, motivados en la mayoría de los casos por el hecho de agradecer 0 solicitar algún favor a la imagen.

En las celebraciones también participan activamente la Alcaldía de Xochimilco como órgano político-administrativo, apoyando a la mayordomía en diversas tareas como la seguridad, la logística de algunos eventos importantes del ciclo ritual y la difusión de la tradición a través de la Dirección de Turismo. En materia de seguridad, la Alcaldía colabora con la mayordomía proporcionando elementos de Protección Civil y Seguridad Publica, para que apoyen en las labores de cierre de avenidas y resguardo de las personas que asisten a las fiestas y procesiones del Niñopa, las cuales suelen desarrollarse en espacios públicos de Xochimilco y son multitudinarias. Durante algunos de los eventos más importantes del ciclo ritual, como el Día de la Candelaria, la Alcaldía facilita a la mayordomía una serie de recursos materiales y humanos, como templetes, lonas, mamparas, sillas y el sonido que se colocan en el atrio de la Parroquia de San Bernardino de Siena para el cambio de mayordomía. En este y otros actos también envía sanitarios móviles, ambulancias y miembros del cuerpo de bomberos. 


\section{ASPECTO METODOLÓGICO:}

Por un lado encontramos el comportamiento del consumidor que gira a través de la fe y del sentido de pertenencia a la comunidad, en donde, estas tradiciones religiosas son un vínculo que les permite relacionarse con el grupo, aunque para ser el mayordomo pasen más de 40 años, es un privilegio y un honor que sean considerados, no importando, que tengan que reunir una importante cantidad de dinero y no tengan los recursos económicos para hacerlo; toda la población de esta localidad contribuye para que los festejos sean lo mejor, aportando dinero, trabajo y servicios a la comunidad.

Independientemente de los festejos propios de la devoción, existen aspectos mercadológicos alrededor de los eventos principales, donde participan activamente las autoridades del gobierno civil que reconocen que el Niñopa moviliza a un gran número de personas en Xochimilco, la Alcaldía se muestra respetuosa de las tradiciones de los habitantes y utiliza la imagen del Niñopa para incrementar la actividad turística. colabora en los festejos a través de su página en internet. carteles, guías turísticas, tren ligero, mostrando elementos que forman parte de la identidad xochimilca y su patrimonio cultural tangible e intangible con lo que promueve el turismo al municipio.

Año con año la celebración es más extravagante. El gasto de los juegos pirotécnicos supera los cien mil pesos, tan sólo por un día, el mayordomo hace un gasto excesivo en cada una de las celebraciones. La comunidad brinda apoyos indirectos que consisten en, por ejemplo, cuando una persona sabe que los mayordomos tienen algún tipo de negocio, dicha persona muestra preferencia en comprar los productos que los mayordomos ofrecen, en lugar de comprar en otras tiendas que podrían llegar a dar los precios más bajos. Esto se debe a que muchos devotos ven en los mayordomos a personas que benefician a la comunidad al momento de desempeñar su mayordomía.

La imagen recibe a diario donativos de manera voluntaria de parte de quienes lo visitan ya sea en casa del mayordomo o en el lugar que le toca visitar cada día, el Niñopa cuenta con dos cofres, uno se queda en la casa de los mayordomos y otro lo acompaña a donde él va de visita, el nivel de devoción y el agradecimiento que se le tiene a la imagen influye mucho en el tipo de donativo monetario que a ésta se le da.
Aunado a una amplia oferta cultural que se lleva a cabo el 2 de febrero en el centro histórico, como conciertos, exposiciones pictóricas y fotográficas como "Las Flores a través del Tiempo" y talleres de pintura, con lo cual se benefició a 6000 personas aproximadamente, entre turistas y nativos de Xochimilco.

Durante el año del 2018 que se informa se recibió la visita de 74,028 turistas nacionales e internacionales que acudieron a Xochimilco mediante agencias de viajes y 301,657 por conocimiento o recomendación. Además, en los módulos de información turística se atendieron a 4,877 personas y se brindó el servicio de sanitarios a 69,666 visitantes.

De manera monetaria reciben un ingreso a los negocios locales registrados como de los prestadores de servicios de los embarcaderos Nuevo Nativitas, San Cristóbal, Uniones de vendedores de refrescos y/o cervezas, dulces cristalizados, flores y Unión de Guías; de igual forma se realizaron 30 verificaciones al equipo de trabajo de servicios pertenecientes al embarcadero Salitre, Cuemanco, Unión de Vendedores de Refrescos y Cervezas, Unión de Norteños, Vendedores de Elotes y Unión filarmónicos; se efectuó la entrega 55 cédulas de registro a prestadores de la Unión de Norteños, Embarcaderos Nuevo Nativitas, Salitre, Belem, Cuemanco, y Fernando Celada

En todas estas celebraciones se encuentra inmersa la mercadotecnia, aunque no sea llamada de esta forma; por ejemplo, en los rituales que maneja, en la planeación y la organización para que la fiesta se realice, en la comercialización de un gran número de productos que son necesarios para llevar a cabo los festejos, en el número de atracciones secundarias que derivan de estas celebraciones, como son la puesta de ferias, juegos mecánicos, mayor consumo de alimentos, de ropa, de alojamiento, entre muchos otros productos que son derivados de estas celebraciones religiosas. 


\section{CONCLUSIONES:}

El caso aquí presentado es un ejemplo de cómo la mercadotecnia está presente en las festividades religiosas, que son parte importante de la cultura y tradición mexicana, en muchas localidades es el punto de reunión y festejo esperado por toda la comunidad en donde — con la idea de hacer un homenaje al santo patrono del pueblose lleva a cabo la celebración más importante, en la cual se reúnen no sólo los habitantes de esa comunidad, sino de otras poblaciones que vienen ex profeso a la celebración, siendo la festividad religiosa un atractivo turístico que genera una fuente significativa de recursos, por los permisos que otorgan para instalar feria, palenque, autorizar pelea de gallos, charreadas, corridas de toros, jaripeos, terrazas (lugares de venta de bebidas alcohólicas), tianguis, juegos mecánicos. Para la Iglesia católica, la fiesta es la mejor ocasión del año para recibir donativos y limosnas, en dinero y en especie, además de peticiones de misas y celebraciones particulares satisfaciendo las necesidades espirituales de la comunidad

Aunque la forma en cómo se lleva a cabo esta celebración no sigue un plan formal de mercadotecnia y se realiza en forma empírica, sí encontramos elementos de la mercadotecnia como la existencia de un proceso que se materializa en el análisis de mercados, la planeación y organización del evento, planteamiento de las estrategias de comunicación, logística de la celebración, control y evaluación de la celebración. Vemos que en estas festividades religiosas hay una importancia mercadológica, lo que genera una derrama económica de los habitantes de la localidad, así como en el impacto social y cultural de las mismas.

\section{CONCLUSIONES:}

El caso aquí presentado es un ejemplo de cómo la mercadotecnia está presente en las festividades religiosas, que son parte importante de la cultura y tradición mexicana, en muchas localidades es el punto de reunión y festejo esperado por toda la comunidad en donde — con la idea de hacer un homenaje al santo patrono del pueblose lleva a cabo la celebración más importante, en la cual se reúnen no sólo los habitantes de esa comunidad, sino de otras poblaciones que vienen ex profeso a la celebración, siendo la festividad religiosa un atractivo turístico que genera una fuente significativa de recursos, por los permisos que otorgan para instalar feria, palenque, autorizar pelea de gallos, charreadas, corridas de toros, jaripeos, terrazas (lugares de venta de bebidas alcohólicas), tianguis, juegos mecánicos. Para la Iglesia católica, la fiesta es la mejor ocasión del año para recibir donativos y limosnas, en dinero y en especie, además de peticiones de misas y celebraciones particulares satisfaciendo las necesidades espirituales de la comunidad

Aunque la forma en cómo se lleva a cabo esta celebración no sigue un plan formal de mercadotecnia y se realiza en forma empírica, sí encontramos elementos de la mercadotecnia como la existencia de un proceso que se materializa en el análisis de mercados, la planeación y organización del evento, planteamiento de las estrategias de comunicación, logística de la celebración, control y evaluación de la celebración. Vemos que en estas festividades religiosas hay una importancia mercadológica, lo que genera una derrama económica de los habitantes de la localidad, así como en el impacto social y cultural de las mismas. Agradecimiento a la estudiante Brenda Monserrat Berrocal Reyes por su colaboración en este proyecto.

\section{REFERENCIAS:}

Abreu, Madalena (2006). The brand positioning and image of a religious organization: an empirical analysis, International Journal of Nonprofit and Voluntary Sector Marketing, London: May 2006. Vol. 11, Iss. 2; pp. 139-146.

Aguilar, José de Jesús (2008). Los laicos y la mercadotecnia o la Iglesia necesitan mejores vendedores, San Pablo, Comunidad Evangelizadora http://www.cesanpablo.org/pdf/laicos.pdf, consultado el 3 de marzo del 2008.

Hamberg, Eva M., \& Pettersson, Thorleif. (2001). The Religios Market: Denominational Competition and Religios Participation in Contemporary Sweden, Journal for the Scientific Study of Religion, 33(3), pp. 205-216.

Hansen, Scott W., Ross Woolridge, Barbara (2002). An empirical investigation of complaint behavior among church members, Journal of Consumer Satisfaction, Dissatisfaction and Complaining Behavior. Vol. 15 pp. 33-51. 
INEGI, censo de población (2010) http://internet.contenidos.inegi.org.mx/contenido s/productos/prod_serv/contenidos/espanol/bvin egi/productos/censos/poblacion/2010/panora_r eligion/religiones_2010.pdf consultado 12 de octubre de 2018

Kotler, P., \& armstrong, G. (2012). Fundamentos de marketing, 14a. edición. México. Editorial Pearson

Landázuri Benítez, G. (2014). Tiempos, espacios y sentidos de las fiestas religiosas en San Gregorio Atlapulco, México. Perspectivas sociales, 16(2), 81-101.

Marketingreligioso

https://prezi.com/wp6zqdfa7oat/marketingreligiosol , consultado 26 de agosto de 2018

Mexicodesconocido(2009),http://www.mexicodesconocido.c om.mx/ninopan-peregrino-en-los-barrios-dexochimilco-distritofederal. Consultado 24 de agosto 2018

Niñopa (2018) imagen http://www.adn40.mx/noticia/cultura/nota/201704-07-16-17/conoce-al-ninopa--el-ninomilagroso-de-xochimilcol, consultado el 16 de octubre de 2018.

Pueblosmexico

http://www.pueblosmexico.com.mx/imprimir(2018) pueblo.php?id_article=24872, consultado $12 \mathrm{de}$ octubre de 2018.

Reyes, Eduarda (2018). Participante como chinela en las festividades del Niñopa desde 1997 hasta el 2002, Entrevista realizada el 17 de octubre de 2018.

Salles, V., \& Arce, J. M. V. (1997). En muchos lugares y todos los días: vírgenes, santos y niños Dios: mística y religiosidad popular en Xochimilco. BPR Publishers.

Sanjay, Mehta S., Gurinderjit B. Mehta (1995). Marketing of churches: An empirical study of important attributes, New York: Vol. 13, Iss. 1; pp. 53-65. 